\title{
Analysis of the microbial community associated with a bioprocess system for bioremediation of thiocyanate- and cyanide-laden mine water effluents
}

\author{
Rob Huddy ${ }^{1}$, Rose Kantor ${ }^{3}$, Wynand van Zyl ${ }^{1}$, Robert P. van Hille ${ }^{1}$, Jill \\ Banfield $^{2}$ and Susan T.L. Harrison ${ }^{1 *}$ \\ ${ }^{1}$ Centre for Bioprocess Engineering Research (CeBER), Department of Chemical \\ Engineering, University of Cape Town, South Africa. \\ ${ }^{2}$ Department of Earth and Planetary Science, University of California, Berkeley, USA. \\ ${ }^{3}$ Department of Plant and Microbial Biology, University of California, Berkeley, USA. \\ *Correspondence: sue.harrison@uct.ac.za
}

Keywords: Thiocyanate, cyanide, bioprocess, bioremediation, biofilm

\begin{abstract}
Gold extraction by cyanidation from refractory gold ores results in the formation of thiocyanate- and cyanide-contaminated wastewater effluents that must be treated before recycle or discard. Activated sludge processes, such as ASTERTM, can be used for biodegradation of these effluent streams. The destruction of these compounds is catalyzed by a mixed microbial culture, however, very little is known about the community composition and metabolic potential of the thiocyanate- and cyanide-degrading microorganisms within the community. Here we describe our on-going attempts to better understand the key microorganisms, within the ASTER ${ }^{\mathrm{TM}}$ bioprocess, that contribute to the destruction of thiocyanate and cyanide, and how this knowledge relates to further process optimisation.
\end{abstract}

\section{Introduction}

The reaction between cyanide $\left(\mathrm{CN}^{-}\right)$and residual sulfur species, during the processing of refractory gold ores, results in a tailings effluent stream containing thiocyanate $\left(\mathrm{SCN}^{-} ;>300\right.$ $\mathrm{mg} / \mathrm{L})$ and residual $\mathrm{CN}^{-}(>20 \mathrm{mg} / \mathrm{L})[1]$. Due to their toxicity, the presence of residual $\mathrm{CN}^{-}$, metal cyanide complexes and $\mathrm{SCN}^{-}$the release of effluent water to the environment is prohibited. The Activated Sludge Tailing Effluent Remediation (ASTER ${ }^{\mathrm{TM}}$ ) process is an example of a biologically-catalysed process that was developed to remediate $\mathrm{CN}^{-}$and $\mathrm{SCN}^{-}$ containing effluents (Fig. 1). The ASTER ${ }^{\mathrm{TM}}$ process was developed, as a collaborative project between Gold Fields and BHP Billiton, in the mid 1990's, to treat process water from BIOX $^{\circledR}$ operations [1]. ASTER ${ }^{\mathrm{TM}}$ aims to facilitate comprehensive destruction of $\mathrm{SCN}^{-}$and $\mathrm{CN}^{-}$contaminated wastewater prior to environmental discard and ultimately enable the recycling of process water within the plant to improve the water balance and improve effluent water quality for environmental disposal. ASTER ${ }^{\mathrm{TM}}$ technology is currently employed at a number of commercial mining operations worldwide and effectively reduces the $\mathrm{CN}^{-}$and $\mathrm{SCN}^{-}$concentrations to $<1 \mathrm{mg} / \mathrm{L}[2]$. 

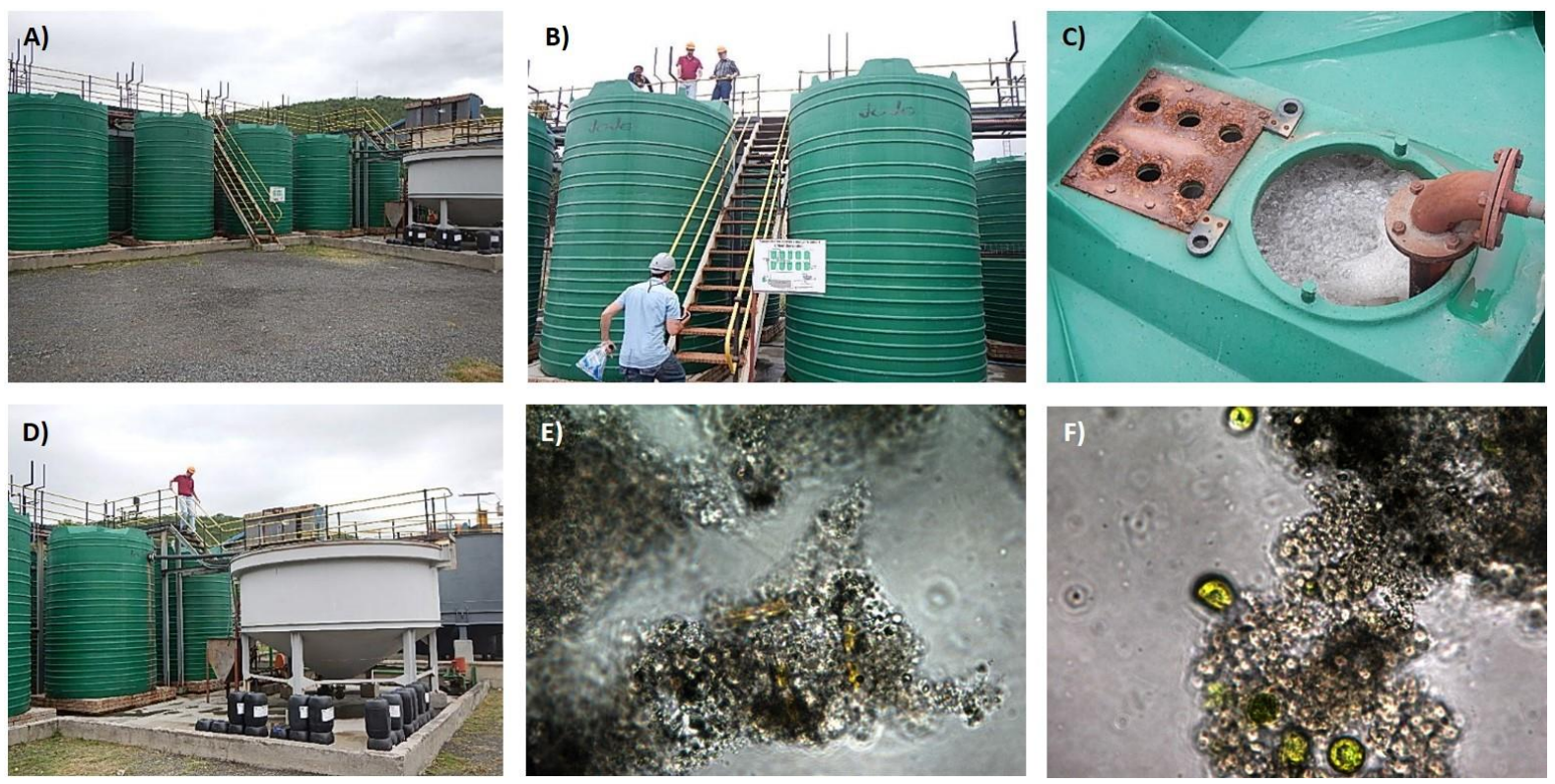

Figure 1. The Consort ASTER ${ }^{\mathrm{TM}}$ Plant, South Africa (A-D) showing the primary and secondary reactors. Light microscope images (Magnification x100) of suspended floc's, densely packed with a variety of microorganisms, from the Consort ASTER ${ }^{\mathrm{TM}}$ Plant.

The ASTER ${ }^{\mathrm{TM}}$ process relies on a complex consortium of microorganisms, in suspended flocs or attached biofilm, to metabolise $\mathrm{SCN}^{-}$(Equations 1-3) and $\mathrm{CN}^{-}$(Equations 4 and 5), yielding sulfate and ammonium.. The formation of biofilm and flocs within the system assist with the efficient retention of the biological catalysts for $\mathrm{SCN}^{-}$and $\mathrm{CN}^{-}$destruction. Furthermore, the microbial communities associated with biofilm and flocs represent a reservoir of microbial diversity for the continuous operation of this system. This leads to a robust commercial bioprocess capable of treating dynamic wastewater streams.

$$
\begin{aligned}
& \mathrm{SCN}^{-}+3 \mathrm{H}_{2} \mathrm{O}+2 \mathrm{O}_{2} \rightarrow \mathrm{CNO}^{-}+\mathrm{HS}^{-} \\
& \mathrm{HS}^{-}+2 \mathrm{O}^{2} \rightarrow \mathrm{SO}_{4}^{2-}+\mathrm{H}^{+} \\
& \mathrm{CNO}^{-}+3 \mathrm{H}^{+}+\mathrm{HCO}_{3}^{-} \rightarrow \mathrm{NH}_{4}^{+}+2 \mathrm{CO}_{2} \\
& \mathrm{HCN}+2 \mathrm{H}_{2} \mathrm{O} \rightarrow \mathrm{HCOOH}^{-} \mathrm{NH}_{3} \\
& \mathrm{HCN}+\mathrm{H}_{2} \mathrm{O} \rightarrow \mathrm{HCONH}_{2}
\end{aligned}
$$

Equation 1

Equation 2

Equation 3

Equation 4

Equation 5

Previous research has linked enhanced $\mathrm{SCN}^{-}$destruction rates to the process operating conditions and increased biomass loading [3]. The microbial ecology of the ASTER ${ }^{\mathrm{TM}}$ process has been investigated, using 16S rRNA gene surveys and metagenomics, and revealed to be far more complex than previously reported [1,4,5,6]. Collectively these investigations provide detailed information on the diversity and composition of the community and of the abundant microbial community members.

\section{Experimental Setup}

Microbial culture. The microbial consortium was collected from the ASTER ${ }^{\mathrm{TM}}$ plant, Barberton Mines, Consort Plant, South Africa. The stock culture was maintained in a $1 \mathrm{~L}$ continuous glass stirred tank reactor connected to a $2 \mathrm{~L}$ glass clarifier unit. The stock reactor 
was continuously fed with reactor media $[0.15 \mathrm{~g} / \mathrm{L}$ molasses, $0.010 \mathrm{~g} / \mathrm{L} \mathrm{P}$ provided as a phosphate salt. and 1,200 mg/L SCN $\left.{ }^{-}(\mathrm{pH} 7.00 \pm 0.02)\right]$. Samples were removed aseptically from the stock reactor, at regular intervals. The $\mathrm{pH}$ was measured prior to batch $\mathrm{SCN}^{-}$ analysis by high performance liquid chromatography (HPLC).

Ecology and functional annotation of the microbial community. The stock reactor was sampled for 16S rRNA genes [4] and metagenomic surveys [5] as a means of monitoring the microbial community associated with the laboratory stock culture. Total genomic DNA was extracted from sludge harvested from the stock reactor [4,5]. The 16S rRNA genes were PCR amplified using universal bacterial 16S rRNA primers, before being sequenced [4]. In addition, the genomic DNA was subjected to Illumina ${ }^{\circledR}$ library preparation and sequencing, using an insert-size of $500 \mathrm{bp}$ and read length of $100 \mathrm{bp}$ [5]. The metagenomic sequences were processed, assembled and annotated, before being assigned to putative bins on the basis of shared characteristics.

Metabolic analysis. Metabolic pathways were predicted, from sequences within each genome, in order to identify metabolic pathways of interest and the potential role(s) of the microorganisms that contain these pathways in this system [5]. Of particular interest were genes and pathways potentially involved in breakdown of $\mathrm{SCN}^{-}, \mathrm{CN}^{-}$and their degradation products, including sulfur, carbon, and nitrogen compounds.

\section{Results}

The $\mathrm{SCN}^{-}$reactor degradation performance prior to sampling was stable over an extended period of continuous operation (Figure 1). Biomass, in the form of a thick biofilm attached to the reactor walls, baffles and impeller, was observed to begin accumulating when the $\mathrm{SCN}^{-}$ loading reached $100 \mathrm{mg} / \mathrm{L} . \mathrm{h}$ (data not shown).

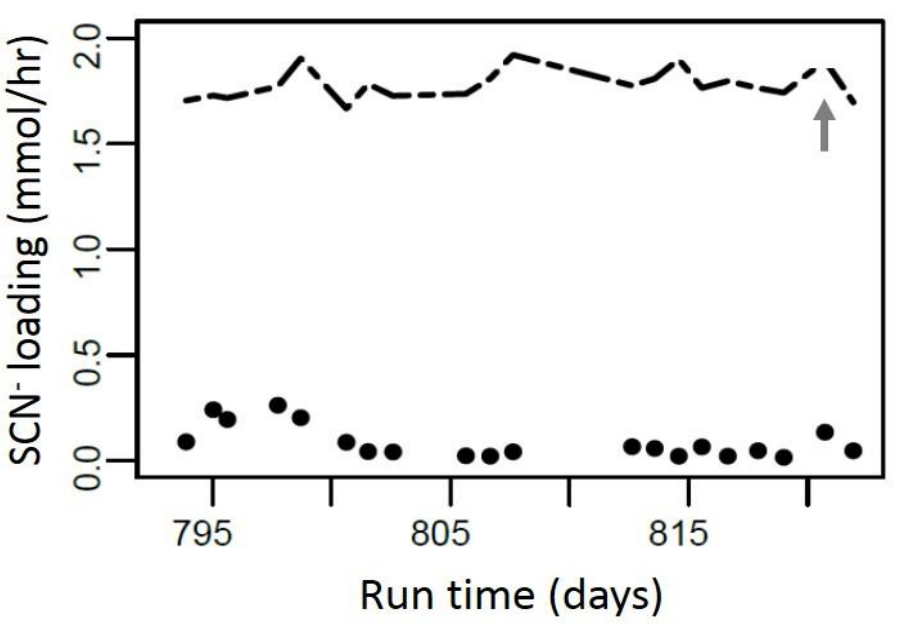

Figure 2. Reactor performance, of the $\mathrm{SCN}^{-}$degrading stock culture, over an extended period of time. $\mathrm{SCN}^{-}$loading into the reactor was achieved by $\mathrm{SCN}^{-}$addition to the reactor feed. Indicated are the rates of SCN- being fed into the system $(-)$ and the residual $\mathrm{SCN}^{-}$present in the effluent $(\bullet)$. Sampling of biomass from the reactor, for metagenomic sequencing, was performed where indicated $(\rightarrow)$.

Overall, based on the metagenomic approach employed in this study, the microbial community in the SCN- reactor was far more complex than previously reported. Rank abundance analysis, based on assembled and binned metagenomic data, demonstrated the dominance of Thiobacillus spp. (Figure 3). The survival and proliferation of multiple Thiobacillus spp. under conditions of high $\mathrm{SCN}^{-}$loading, indicates tolerance to and/or the capacity to use $\mathrm{SCN}^{-}$. In particular, the two highest abundance Thiobacillus spp. genomes 
present in this system contain the genes and pathways potentially involved in breakdown of $\mathrm{SCN}^{-}$and its degradation products.

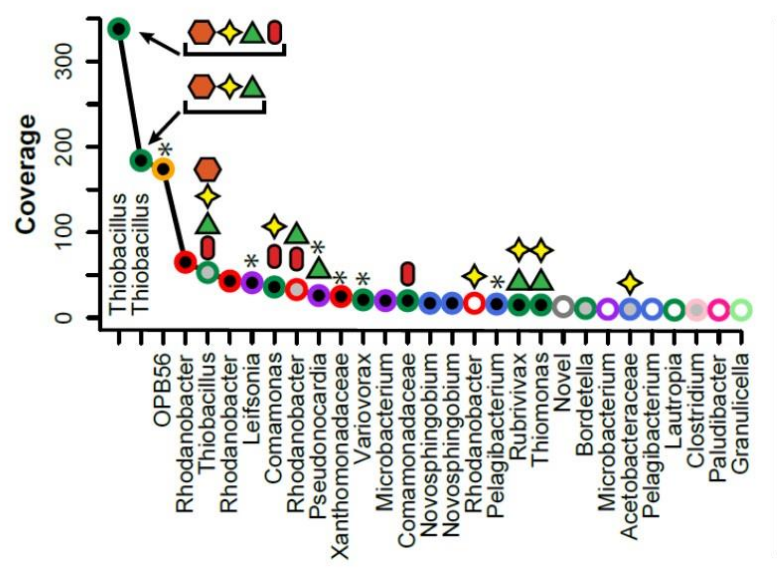

\begin{tabular}{|c|c|}
\hline $\begin{array}{l}\text { Phylogenetic classification } \\
\text { Acidobacteria } \\
\text { O Actinobacteria } \\
\text { Olphaproteobacteria } \\
\text { Bacteroidetes } \\
\text { O Betaproteobacteria } \\
\text { Deltaproteobacteria } \\
\text { O Eukaryote } \\
\text { O Gammaproteobacteria } \\
\text { Gemmatimonadetes } \\
\text { Firmicutes } \\
\text { Nitrospirae } \\
\text { Novel } \\
\text { OPB56 }\end{array}$ & $\begin{array}{l}\text { Metabolic potential } \\
\text { and bin information } \\
\square \text { Thiocyanate degradation } \\
\diamond \text { Sulfide oxidation } \\
\triangle \text { Carbon fixation } \\
0 \text { Nitrite denitrification }\end{array}$ \\
\hline
\end{tabular}

Figure 3. Rank abundance and metabolic potential for organisms in the reactor treating $\mathrm{SCN}^{-}$. The genome bins are ordered from highest to lowest coverage as a proxy for abundance within the system. The outer circle colour indicates phylogeny, and circle fill indicates genome completeness measured by presence or absence of 51 conserved singlecopy marker genes. Symbols represent metabolic potential in organisms based on the presence of all associated functional genes in a given bin.

\section{Conclusions}

This cross-disciplinary research suggests that due to the apparent dominance of autotrophic $\mathrm{SCN}^{-}$degraders within the SCN-degrading system. Furthermore, our on-going research is focused on the drivers leading to the formation of the microbial biofilm, and the role that these sessile microbial communities play, within the current reactor configurations, to ensure efficient $\mathrm{SCN}^{-}$degradation kinetics. The spatial distribution of key microorganisms within

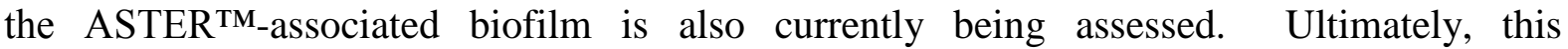
information will be chelated and applied to inform further optimisation of the bioprocess for efficient treatment of contaminated mining wastewater effluents, including rational reactor design and a detailed understanding of the response of the microbial community to process perturbations.

\section{References}

[1] C van Buuren, N Makhotla, and JW Olivier (2011) Proceedings of the ALTA 2011 Nickel-Cobalt-Copper, Uranium and Gold Conference.

[2] http://www.biomin.co.za/pdf/aster_brochure.pdf

[3] AW van Zyl, University of Cape Town, South Africa (unpublished data).

[4] RJ Huddy, AW van Zyl, RP van Hille and STL Harrison (2015) Miner. Eng. Vol. 76, p 65-71 http://dx.doi.org/10.1016/j.mineng.2014.12.011

[5] R Kantor, AW van Zyl, R van Hille, BC Thomas, STL Harrison and JF Banfield (In prep) Metagenomic analysis of a thiocyanate and cyanide biodegrading consortia.

[6] C.A. du Plessis, P. Barnard, R.M. Muhlbauer, K. Naldrett. Empirical model for autotrophic degradation of thiocyanate in an activated sludge reactor. Lett. Appl. Microbiol. Vol. 32, p 103-107. 